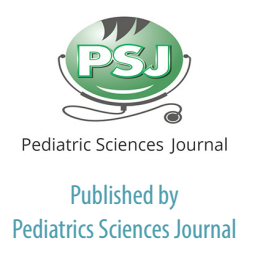

'Department of Pediatric Allergy Immunology, Saiful Anwar Hospital, Faculty of Medicine, Universitas Brawijaya, Indonesia ${ }^{2}$ Medical Student, Department of Pediatric, Faculty of Medicine, Universitas Brawijaya, Malang, Indonesia

*Corresponding to:

Desy Wulandari; Department of Pediatric Allergy Immunology, Saiful Anwar Hospital, Faculty of Medicine, Universitas Brawijaya, Indonesia;

desywulandari@ub.ac.id

Received: 2021-03-16

Accepted: 2021-05-20

Published: 2021-06-01

\section{An Eleven Year Old Boy with Drug Rash with Eosinophilia and Systemic Symptoms (DRESS)}

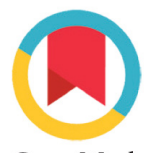

CrossMark

\author{
Desy Wulandari ${ }^{1 *}$, Wisnu Barlianto ${ }^{1}$, Nisak Humairok ${ }^{2}$
}

\begin{abstract}
Introduction: The prospective studies have estimated that the DRESS syndrome incidence rate is about 1 per 1000 to 10,000 with the mortality rate is to be around $10 \%$ to $20 \%$.

Case: We have been reported a case of DRESS in an eleven-year-old boy who came to the emergency room with the chief complaint of maculopapular rash in the body that had been happened for three days. The rash was first appeared in the arms area and thus spread to the trunk, abdomen, and lower extremities. The erythema was well-demarcated, purplish in color. There was a history of fever a week before admission which reached $40^{\circ}$ Celcius. There are multiple histories of drug administration, either orally or intravenously to this patient, and made the diagnosis of drug reaction is highly possible. The management of these patients consists of suspending suspected drugs and implementing supportive measures.

Conclusion: Regarding pharmacological treatment, the use of systemic corticosteroids for a prolonged period with a gradual decrease is suggested, to avoid relapses.
\end{abstract}

Keywords: Drug rash with eosinophilia and systemic symptoms (DRESS), pediatric, allergy

Cite This Article: Wulandari, D., Barlianto, W. Humairok, N. 2021. An Eleven Year Old Boy with Drug Rash with Eosinophilia and Systemic Symptoms (DRESS). Pediatrics Sciences Journal 2(1): 4-9.

\section{INTRODUCTION}

Drug rash with eosinophilia and systemic symptoms (DRESS) is an adverse reaction term that is currently used to describe a hypersensitivity reaction. DRESS syndrome is a delayed-type IVb hypersensitivity reaction thought to be mediated by antiviral $\mathrm{T}$ cells. It is a severe, idiosyncratic multisystem reaction to a drug, characterized by fever, skin rash, lymphadenopathy, hematological abnormalities, and internal organ involvement. ${ }^{1}$ DRESS syndrome can be difficult to diagnose because of its nonspecific presentation. Moreover, it often is asymptomatic until a considerable amount of time has passed after the initial drug exposure. The pathogenesis of DRESS is unclear, although several models have been proposed, and it may have a genetic origin. ${ }^{2}$

The incidence rate of DRESS syndrome is unknown, prospective studies have estimated it to be about 1 per 1000 to 10,000 individuals exposed to commonly associated drugs. The mortality rate is estimated to be around $10 \%-20 \%$. Several common drugs and drug categories have been associated with this condition, including antiepileptics, allopurinol, sulfonamides, and various antibiotics. Moreover, the consensus has not been established on the management and treatment of DRESS syndrome. The only management step that appears to be universally accepted is cessation of the causative antibiotics agent. ${ }^{2}$

DRESS syndrome has been noted as a great mimicker of other conditions. DRESS syndrome may be confused with an array of infectious, rheumatologic, and hematologic diseases. A complete discussion of febrile exanthems in children would be difficult. Clinicians who treat children need to develop heuristics to aid in sorting out the typical features of diseases from simple viral exanthems to toxic shock syndrome and hundreds of others. The important element is to add DRESS syndrome to those diagnostic considerations. In children especially, DRESS syndrome shares feature with many serious illnesses such as Kawasaki disease, staphylococcal scalded skin syndrome (SSSS), or systemic juvenile inflammatory arthritis.
The purpose of this case is to discuss further a rare disease which symptoms are very often encountered in daily practice. The aim is to widen the horizon of knowledge of doctors that the symptoms of fever and rash can be very diverse, not only dominated by infectious diseases but also can be a symptom of an allergy to certain drugs, as happened in DRESS.

\section{CASE PRESENTATION}

An 11-year-old male came to the emergency unit in Saiful Anwar General Hospital with the chief complaint of rash in the skin that had been happened for three days. The rash was first appeared in the arms area and thus spread to the trunk, abdomen, and lower extremities. The erythema was well-demarcated, purplish in color, and unpalpable. There was no itchy or painful feeling in the rash area. The purplish color in the skin was not disappeared during palpation (Figure 1). The complete blood count of the patient showing markedly leukocytosis with eosinophil predominant, the liver function test showed markedly elevated 


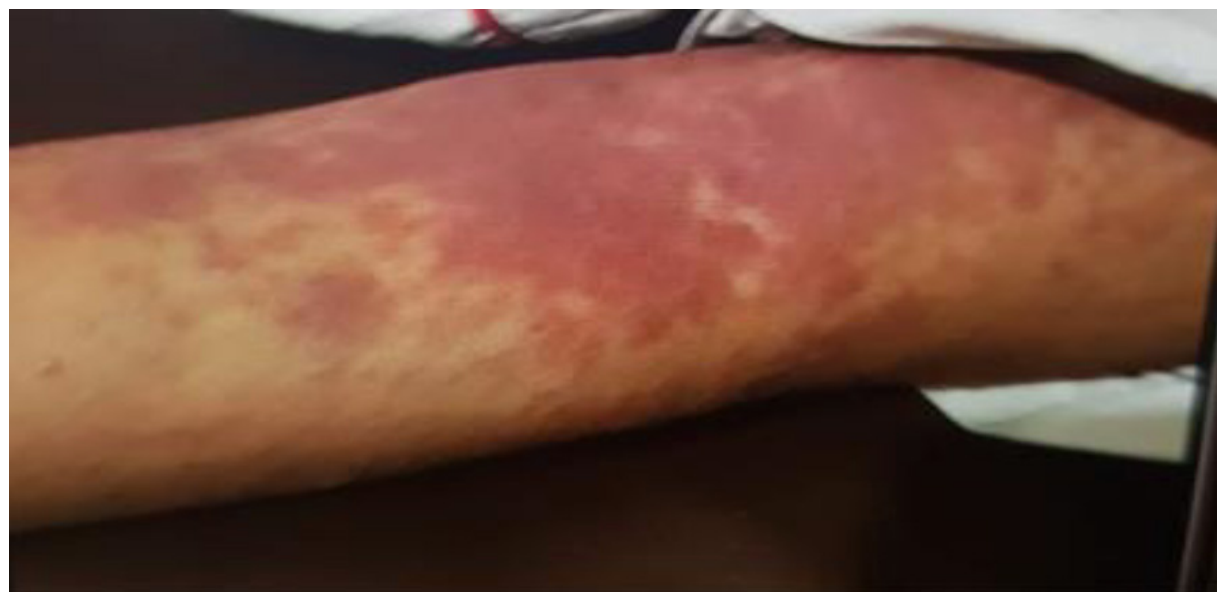

Figure 1. Skin Condition The skin rash was appeared as multiple purple plaques along the extremities which are not disappeared with pressure.

\begin{tabular}{|c|c|}
\hline $\begin{array}{l}\text { Rash in the hand, } \\
\text { vesicles, and } \\
\text { diagnosed as } \\
\text { herpes viral } \\
\text { infection }\end{array}$ & $\begin{array}{l}\text { Rash started to appear } 4 \text { days } \\
\text { after ceftriaxone administration } \\
\qquad \begin{array}{l}\text { fever }\end{array}\end{array}$ \\
\hline $\begin{array}{l}\text { Medication continous for } 4 \text { weeks } \\
\text { without anv prescriptions }\end{array}$ & 7 days \\
\hline
\end{tabular}

Figure 2. The timetable of many different medications taken by the patient. There were history of multiple antibiotics use for long period of time at previous hospital. The fever occurred several days after the rash developed.

AST and ALT indicating an acute liver injury can be seen in Table 1 . The skin rash was improved after the administration of intravenous methylprednisolon with the daily dose $1 \mathrm{mg} / \mathrm{kgBW}$.

The patient has a normal and regular history of birth, nutrition, and development. Past medical history revealed that there was no history of allergy and food allergy. But there were histories of multiple antibiotics administration prior to the hospitalization in Saiful Anwar General Hospital (Figure 2). There was no similar medical history in the family mimicking the symptoms found in the child. The patient had a fever seven days before admission to the emergency room in Saiful Anwar General Hospital. The highest temperature ever measured was $41^{\circ}$ Celcius and was not improved by giving paracetamol. Neither cough nor conjunctivitis was present. The patient's mother also complained of the patient's swollen face. After 3 days in the private hospital, the fever has been treated, and the swelling was finally disappeared. After 3 days of being at home, the patient experienced a high fever and peaked at around $40^{\circ}$ celcius. The parents took the patient to the General Hospital for further management.

\section{DISCUSSION}

The patient came to the emergency room complaining about the rash affecting the whole body. The maculopapular rash was multiple in size and purplish in color. Only a few pediatric skin disorders are acute, some (including varicella, urticaria, herpetic gingivostomatitis or bullous impetigo) can be severe, but not many are potentially life-threatening. The life-threatening skin diseases include some rare infectious diseases such as staphylococcal scalded skin syndrome, Kaposi's varicelliform eruption, varicella with complications and cellulitis, and inflammatory diseases such as angioedema, erythema multiforme or Kawasaki
Table 1. Laboratory Findings

\begin{tabular}{ll}
\hline Complete Blood Count & \\
\hline Hemoglobin & 11.5 \\
Leucocyte & $\mathbf{1 3 . 8 3 0}$ \\
Hematocrite & $34.2 \%$ \\
Trombocyte & 142.000 \\
MCV & 76.90 \\
MCH & 25.80 \\
MCHC & 33.60 \\
Eosinophil & $5.1 \%$ \\
Basophil & $0.1 \%$ \\
Neutrophil & $52.1 \%$ \\
Lymphocyte & $34.3 \%$ \\
Monocyte & $8.4 \%$ \\
AST & 332 \\
ALT & $\mathbf{3 9 0}$ \\
Albumin & 3.68 \\
ESR & $61 \mathrm{~mm} / \mathrm{jam}$ \\
CRP & $0.33 \mathrm{mg} / \mathrm{dL}$ \\
\hline
\end{tabular}

disease. Some clinical features are very likely to appear in many rheumatologic, hematologic, and infectious diseases. The rash which appears in DRESS syndrome could mimic any other diseases.

Fever and rash are common findings in patients presenting to the physicians and emergency department. Although in the majority, the disease is benign and selflimited, sometimes, it may be the first or the only sign of a serious and lifethreatening condition. ${ }^{4}$ For clinical diagnosis of diseases accompanied by a rash and fever, a complete history must be taken, including recent travel, contact with animals, medications, and exposure to forests and other natural environments. In addition, the time of onset of symptoms could be helpful in the clinical diagnosis. Several researches concerned with the basis of morphology, the associated symptoms, and laboratory results concluded that a good correspondence between morphology and etiology was found, and their morphology and their association with pruritus or constitutional symptoms proved to be important diagnostic clues. ${ }^{5}$

The erythemato-pustular and papular patterns were found only in drugrelated cases and in some undiagnosed cases. While the erythematous-vesicular pattern was exclusive to viral infections. Severe pruritus was associated with drug-related exanthems. The distribution of the rash is also important to note by the physician. The primary skin lesion which is very 
Table 2. Common Primary Skin Lesions in Children

\begin{tabular}{ll} 
Lesion type & Description \\
\hline Macule & $\begin{array}{l}\text { Circumscribed area of change in normal color, with no skin elevation or } \\
\text { depression; may be any size }\end{array}$ \\
Papule & Solid, raised lesion up to $0.5 \mathrm{~cm}$ in greatest diameter \\
Nodule & Similar to papule but located deeper in the dermis or subcutaneous tissue \\
Plaque & Elevation of skin occupying a relatively large area in relation to height \\
Pustule & Circumscribed elevation of skin containing purulent fluid of variant character \\
Vesicle & Circumscribed, elevated, fluid containing lesion less than $0.5 \mathrm{~cm}$ in diameter \\
Bulla & Same as vesicle, except lesion is more than $0.5 \mathrm{~cm}$ in gratest diameter \\
\hline
\end{tabular}

common in children were shown in Table 2. Different diseases show a different way of rash distribution. Fever, sore throat, vomiting, diarrhea, fatigue, irritability, anorexia, conjunctivitis, cough, and insomnia all significantly indicated viral infections. ${ }^{5}$

In this patient, according to the through history, there was no history of contact with known viral infection patients such as measles/ morbili, dengue fever, or others. The symptoms were purplish rash accompanied by acute febrile illness. However, there were no other symptoms to support the diagnosis of measles such as cough, coryza, conjunctivitis, and the physical examinations showing the normal limit. There were multiple lymphadenopathies in the bilateral colli area which somehow mimicking other infectious diseases like Rubella/ German measles and infectious mononucleosis. The morbili is also characterized by the presence of prodromal symptoms. The temperature starts to rise again and the rash may be round or oval. Our patient did not develop high grade fever which is followed by a rash in the skin. The rash also did not resolve within few days after the drop of temperature makes it unlikely to be a morbili or measles infection. Rubella also mimicking morbili and it is possible to be one of the differential diagnoses. In rubella, the form of the disease less severe compared to morbili. The rash suddenly appears and rapidly progresses, lasting for about 3 days and then resolved. In this patient, the clinical manifestations occurred over a long period. This patient also develops a morbilliform maculopapular rash like what we found cough, conjunctivitis, and coryza. Multiple lymphadenopathies which are more than 5 nodules appeared in the neck area which also can be found in rubella. Nevertheless, the rash in rubella did not confluence like what we found in this patient.

Besides many infectious diseases, the physician should consider any other rheumatologic disorder such as Steven Johnson Syndrome/SJS or Toxic Epidermolisis Necrosis/TEN. Although there is substantial overlapping in terms of clinical, radiological and histopathological findings, the main differentiation point between these two diseases is the area of epidermal separation on the body surface. Epidermal separation is observed in less than $10 \%$ of the body surface in SJS, in more than $30 \%$ of the body surface in TEN, and in $10-30 \%$ of the body surface in SJS/TEN overlap. In Stevens Johnson syndrome and TEN, cutaneous and mucosal involvement occur following the prodromal period during which nonspecific complaints are observed. The second period during which epidermal separation occurs and vesicles and bullae are formed following the early stage of the disease which is characterized by red-purple maculopapular eruptions. Inflammatory changes including purulent conjunctivitis, erosion, ulcer and crusts may be observed in the eye, mouth, nose, pharynx, esophagus, trachea, gastrointestinal tract, urinary tract, and genital mucosae. ${ }^{6}$

The hallmark of the SJS/TEN is keratinocyte necrosis. In early lesions, apoptotic keratinocytes are located in the basal layer of the epidermis, but in established lesions, there may be overall in morbili or measles. But, we did not find thickness necrosis of the epidermis and subepidermal bullae. A lymphohistiocytic perivascular infiltrate containing a variable number of eosinophils are present in the superficial dermis. ${ }^{7}$ The initial rash of SJS sometimes forms a target-lesion, isn't itchy, and can develop over several hours or even days. The mucosal membranes of our patient, including inside the mouth, throat, eyes, and genital tract are intact. In this patient, there are no signs of epidermal necrosis and involvement of the mucosal membrane which is the hallmark of SJS/ TEN. The onset of the disease also quite distinct compared to the SJS/TEN which usually occur within days and maximum lasts until three weeks. The duration of the skin rash in the patient is longer than what we found in SJS/TEN. The symptoms in this patient occurred gradually. This evidence makes it unlikely to be an SJS.

The rash in DRESS, which usually appears as a non-specific disseminated morbilliform maculopapular rash, is however matches the patient's condition. The rash is present in $95 \%$ of patients, starting on the face and upper trunk, spreading down, and then quickly developing a bluish tint. The eruption suggests a DRESS when affecting more than $50 \%$ of the body surface and/or it includes two or more of the following: facial edema, infiltration, scaling, and purple lesions. Facial edema occurs in about half of cases; it is symmetrical, persistent, and is accompanied by erythema. Almost half of the patients displayed swelling and pain of the mucous membranes. The DRESS is predominantly distinct from SJS or TEN. The disease affecting usually just one mucosa (most often the mouth and pharynx), without progressing to erosion, unlike the SJS or TEN.?

Henoch Schonlein Purpura (HSP) has become one of the diseases with notable skin manifestations. HSP is an IgA-mediated small vessel vasculitis that affects multiple organ systems including the skin, joints, gastrointestinal tract, and kidneys. The disease classically presents following as an upper respiratory infection with palpable purpura involving the lower extremities. Lesions are not restricted to this area. Typical skin manifestations of HSP include palpable purpura and petechiae. However, erythematous maculopapular 
and urticarial lesions have also been reported. ${ }^{8}$ The diagnosis of HSP is based on the presence of a mandatory finding, which are purpura and petechiae with lower limb predominance. Minimum one out of four criteria has to present. The four criteria are including diffuse abdominal with acute onset, histopathology showing leukoclastic vasculitis or proliferative glomerulonephritis with $\operatorname{IgA}$ dominant deposits, Arthritis/arthralgia of acute onset, hematuria or proteinuria as evidence of renal involvement. ${ }^{9}$ However, in this patient, the diagnosis of HSP can be excluded.

Kawasaki disease (KD), which is an acute systemic vasculitis also known as mucocutaneous lymph node syndrome, is the most common cause of acquired heart disease in children. Potentially serious complications from $\mathrm{KD}$ include coronary artery inflammation, aneurysm, and possible aneurysm rupture, myocarditis, thrombotic occlusion of the aneurysm, and congestive heart failure. Whereas the classical diagnostic criteria for $\mathrm{KD}$ as defined by the AHA include the existence of high fever for more than 5 days and the presence of at least 4 of the 5 following criteria: changes in extremities; polymorphous exanthema; bilateral bulbar conjunctival injection without exudates; changes in lips and oral cavity; and cervical lymphadenopathy $(>1.5 \mathrm{~cm}$ diameter). Incomplete $\mathrm{KD}$ can also be diagnosed by the AHA guidelines based on prolonged fever for over 5 days and 2 to 3 of standard clinical features of $\mathrm{KD} .{ }^{10}$ In this patient, we also found many signs of Kawasaki Disease such as prolonged fever, cervical lymphadenopathy, and exanthema. However, the patient underwent the echocardiography examination and the result was no sign of coronary artery disease or the presence of an aneurysm. We also did not find any strawberry tongue, conjunctival redness, or limb swelling. Thereby, the disease is unlikely to be a Kawasaki disease.

Drug induced allergy becomes the most possible cause in this patient related to the previous history of taking many culprit drugs, such as cephalosporins. Approximately $45 \%$ of all adverse drug reactions are manifested in the skin, which occur in $2 \%$ to $3 \%$ of hospitalized patients on drug administration. Drug hypersensitivity reactions can be categorized into immediate reactions and delayed reactions. Immediate reactions occur within minutes or hours of drug exposure. The manifestations of immediate-type reactions range from pruritus, urticaria, angioedema, to anaphylaxis. The delayed-type reactions are primarily T-cell mediated type IV reactions that usually take several days or even weeks to manifest after drug exposure. The manifestations of delayedtype drug hypersensitivity range from mild maculopapular exanthema and fixed drug eruptions to severe cutaneous adverse reactions (SCARs). ${ }^{11}$

In this case, the clear temporal relationship between the onset of drug intake and the appearance of adverse event and the resolution of symptoms following the withdrawal of the suspected drug along with a clinical course of the disease and the investigation data ruling out most of the other probable etiologies was suggestive of probable drug reaction on Naranjo probability scale. Enlarged lymph nodes in this patient (1 point), Eosinophilia (1 point), Rash involving more than $50 \%$ of body surface area (1 point), skin rash suggesting DRESS (1 point). Skin biopsy data were absent (-1 point), Organ involvement (1 point) is highly probable due to elevating liver enzymes. Lymphadenopathy in two different anatomical sites more than $1 \mathrm{~cm}$ in size (1 point), atypical lymphocytes in peripheral smear ( 0 points) in our patient. Rash resolution for more than 15 days (1point), excluding other causes (1 point) added to a score of 7 indicating definite DRESS according to RegiSCAR DRESS validation scoring. Items of signs and symptoms along with laboratory results supporting the diagnosis of DRESS shown in Table 3.

\section{Table 3. RegiSCAR ${ }^{12}$}

\begin{tabular}{|c|c|c|c|c|}
\hline \multirow{2}{*}{ Items } & \multicolumn{3}{|c|}{ Score } & \multirow{2}{*}{ Comments } \\
\hline & -1 & 0 & 1 & \\
\hline Fever $\geq 38.5^{\circ} \mathrm{C}$ & $\mathrm{N} / \mathrm{U}$ & $\mathrm{Y}$ & & \\
\hline Enlarged lymph nodes & & $\mathrm{N} / \mathrm{U}$ & $\mathrm{Y}$ & $>1 \mathrm{~cm}$ and $\geq 2$ different areas \\
\hline $\begin{array}{c}\text { Eosinophilia } \geq 0.7 \times 10^{9} / \mathrm{L} \text { or } \geq 10 \% \text { if } \\
\text { WBC }<4.0 \times 10^{9} / \mathrm{L}\end{array}$ & & $\mathrm{N} / \mathrm{U}$ & $\mathrm{Y}$ & $\begin{array}{l}\text { Score } 2 \text {, when } \geq 1.5 \times 10^{9} / \mathrm{L} \text { or } \geq 20 \% \\
\text { If } \mathrm{WBC}<4.0 \times 10^{9} / \mathrm{L}\end{array}$ \\
\hline Atypical lymphocytosis & & $\mathrm{N} / \mathrm{U}$ & $\mathrm{Y}$ & \\
\hline $\begin{array}{c}\text { Skin rash } \\
\text { Extent }>50 \% \text { of BSA } \\
\text { Rash suggesting DRESS }\end{array}$ & $\mathrm{N}$ & $\begin{array}{c}\mathrm{N} / \mathrm{U} \\
\mathrm{U}\end{array}$ & $\begin{array}{l}\mathrm{Y} \\
\mathrm{Y}\end{array}$ & $\begin{array}{l}\text { Rash suggesting DRESS: } \geq 2 \text { symptoms: purpuric lesions (other } \\
\text { than legs), infiltration, facial edema, psoriasiform desquamation }\end{array}$ \\
\hline Skin biopsy suggesting DRESS & $\mathrm{N}$ & $\mathrm{Y} / \mathrm{U}$ & & \\
\hline Organ involvement & & $\mathrm{N}$ & $\mathrm{Y}$ & Score 1 for each organ involvement, maximal score: 2 \\
\hline Rash resolution $\geq 15$ days & $\mathrm{N} / \mathrm{U}$ & $\mathrm{Y}$ & & \\
\hline Excluding other causes & & $\mathrm{N} / \mathrm{U}$ & $\mathrm{Y}$ & $\begin{array}{c}\text { Score } 1 \text { if } 3 \text { tests of the following tests were performed and all } \\
\text { were negative: HAV, HBV, HCV, Mycoplasma, Chlamydia, ANA, } \\
\text { blood culture }\end{array}$ \\
\hline
\end{tabular}

ANA: anti-nuclear antibody; BSA: body surface area, HAV: hepatitis A virus; HBV: hepatitis B virus; HCV: hepatitis C virus; N: no; U: unknown; WBC: white blood cell; Y: yes. 


\begin{tabular}{|c|c|c|c|c|}
\hline & Question & Yes & No & Don't Know \\
\hline 1. & Are there previous conclusive reports on this reaction? & 1 & 0 & 0 \\
\hline 2. & Did the adverse reaction appear after the suspended drug was administered? & 2 & -1 & 0 \\
\hline 3. & $\begin{array}{l}\text { Did the adverse reaction improve when the drug was discontinued or a specific antagonists was } \\
\text { administered? }\end{array}$ & 1 & 0 & 0 \\
\hline 4. & Did the adverse reaction appear when the drug was readministered? & 2 & -1 & 0 \\
\hline 5. & Are there alternative causes that could on their own have caused the reaction? & -1 & 2 & 0 \\
\hline 6. & Did the reaction reappear when a placebo was given? & -1 & 1 & 0 \\
\hline 7. & Was the drug detected in the blood (or other fluids) in concentrations known to be toxic? & 1 & 0 & 0 \\
\hline 8 & $\begin{array}{l}\text { Was the reaction more severe when the dose was increased or less severe when the dose was } \\
\text { decrease? }\end{array}$ & 1 & 0 & 0 \\
\hline 9. & Did the patient have a similar reaction to the same or similar drug in any previous exposure? & 1 & 0 & 0 \\
\hline 10. & Was the edverse event confirmed by any objective evidence? & 1 & 0 & 0 \\
\hline
\end{tabular}

${ }^{\star}$ Scoring: $\geq 9$ : definite, 5 -8: probable, 1-4: possible, $\leq 0$ : doubtful

According to Naranjo Scale (Table 4), the history taking suggesting the possibility of adverse drug reaction in this patient which induced his elevated liver enzyme. In the previous conclusive report on this reaction (0 points), the adverse reaction appears after the drug was administered ( 2 points), adverse reaction improves when the drug was discontinued or a specific antagonist was administered (1 point), did the adverse reaction was appeared when readministering the drug (0 points), other alternative causes for the reaction ( 2 points), the reaction appears when placebo given (0 points), detection of the toxic drug in the blood (0 points), the reaction was dependent on the dose (0 points), similar reactions to the same drug in previous exposure ( 0 point), and the adverse reaction was confirmed by any objective evidence ( 1 point). The questions added a score of 6 which is probably for the culprit drug administration causing the elevated liver injury in the patient. The most possible culprit drug in this patient is a cephalosporin. The cephalosporin, vancomycin, anti-TB drugs, and NSAIDs were included as major causes of DRESS syndrome in the present study. ${ }^{11}$

From the discussion, we learn that maculopapular rash and fever can be signs of many diseases. The clinician should make a through history taking about the onset of the rash along with the characteristics of the fever in order to make correct temporal relationship. The type of the rash and other organ involvements should not be overlooked to treat the disease. DRESS syndrome is a rare entity in pediatrics. For this reason and for its potential severity, it is a diagnosis that should be considered in children who exhibit exanthema, fever, lymphadenopathy and systemic compromise. Although the most frequent cause is anticonvulsants, cases have been described for several drugs of different nature. The diagnosis is clinical, supported by laboratory tests, and can be supplemented with a skin biopsy in the case of diagnostic doubt. First of all, the management of these patients consists of suspending suspected drugs and implementing supportive measures. Regarding pharmacological treatment, the use of systemic corticosteroids for a prolonged period with a gradual decrease is suggested.

\section{CONFLICT OF INTERESTS}

The authors declare no conflict of interest.

\section{ETHICAL APPROVAL}

There was no ethical approval from the specific organization regarding this publication. However, we have an informed consent form signed by the patient's parents. We described to the patient our plan to publish their child's case as a case report in a scientific journal. This publication aimed to spread awareness of the diagnosis of DRESS in the scope of professional and academic fields. We deliver the information by using Indonesia language.

\section{FUNDING}

There was no financial support for this work.

\section{AUTHOR CONTRIBUTIONS}

All authors equally contribute to this case study from the data acquisition, data analysis, until reporting the results of study through publication.

\section{REFERENCES}

1. Marcus N, Smuel K, Almog M, Prais $\mathrm{D}$, Straussberg $\mathrm{R}$, Landau $\mathrm{D}$, and Scheuerman O. Successful intravenous immunoglobulin treatment in pediatric severe DRESS syndrome. The Journal of Allergy and Clinical Immunology: In Practice 2018; 6(4): 1238-1242.

2. Bommersbach TJ, Lapid MI, Leung JG, Cunningham JL, Rummans TA, and Kung S. Management of Psychotropic DrugInduced DRESS Syndrome: A Systematic Review. In Mayo Clinic Proceedings 2016, June 91(6): 787-801.

3. Moon AT, Castelo-Soccio L, and Yan AC. Emergency department utilization of 
pediatric dermatology (PD) consultations. Journal of the American Academy of Dermatology 2016, 74(6):1173-1177.

4. Saffar MJ, Saffar H, Shahmohammadi S. Fever and Rash Syndrome: A review of clinical practice guidelines in the differential diagnosis. J Pediatr Rev. 2013;1(2):42-54.

5. Kang JH. Febrile illness with skin rashes. Infection \& chemotherapy 2015; 47(3):155-166.

6. Çekiç Ş, Canıtez Y, and Sapan N. Evaluation of the patients diagnosed with Stevens Johnson syndrome and toxic epidermal necrolysis: a single center experience. Turkish Archives of Pediatrics/ Türk Pediatri Arşivi 2016; 51(3): 152.

7. Belver MT, Michavila A, Bobolea I, Feito M, Bellón T, and Quirce S. Severe delayed skin reactions related to drugs in the paediatric age group: a review of the subject by way of three cases (StevensJohnson syndrome, toxic epidermal necrolysis and DRESS). Allergologia et immunopathologia 2016; 44(1):83-95.

8. Duman MA, Duru NS, Caliskan B, Sandikci H, Cengel F. Lumbar Swelling as the unusual presentation of HenochSchonlein Purpura in a child. Balkan Medical Journal 2016 May; 33(3): 360362.

9. Hetland LE, Susrud KS, Lindahl KH, Bygum A. Henoch-Schönlein Purpura: A Literature Review. Acta Derm Venereol 2017; 97: 1160-1166.

10. Choi JE, Kwak Y, Huh JW, Yoo ES, Ryu KH, Sohn S, Hong YM. Differentiation between incomplete Kawasaki disease and secondary hemophagocytic lymphohistiocytosis following Kawasaki disease using $\mathrm{N}$-terminal pro-brain natriuretic peptide. Korean J Pediatr 2018 May;61(5): 167-173.

11. Oshikoya KA, Ogunyinka IA, Ogar CK, Abiola A, Ibrahum A, Oreagba IA. Severe cutaneous adverse drug reactions manifesting as Steven-Johnson syndrome and toxic epidermal necrolysis reported to the national pharmacovigilance center in Nigeria: a database review from 2004 to 2017. Therapeutic Advances in Drug Safety 2020;11: 2042098620905998.

12. Muhammed K, Pillai SS, Nazrin S, Sureshan DN, and Nagesh M. Drug reaction with eosinophilia and systemic symptoms mimicking Kawasaki disease. Indian Journal of Paediatric Dermatology 2017; 18(4): 349.

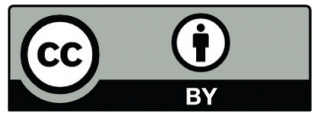

This work is licensed under a Creative Commons Attribution 